Reprinted from Huffman, S., \& Myers, J. E. (1999). Counseling women in midlife: An integrative approach to menopause. Journal of Counseling and Development, 77(3), 258-266. The American Counseling Association. Reprinted with permission. No further reproduction authorized without written permission from the American Counseling Association: http://www.counseling.org/

\title{
Counseling Women in Midlife: An Integrative Approach to Menopause
}

\author{
Shirley B. Huffman and Jane E. Myers
}

Menopause is a normative life transition that is experienced by virtually all women, yet remains poorly understood. The dominance of the biomedical model results in a unidimensional definition of menopause as a bjological event, ignoring the influence of cultural and psychosocial factors. Counselors who use an integrative approach can not only provide accurate biomedical information but also conceptualize menopause as a normative midlife transition. The purpose of this article is to provide a foundation in biomedical issues and to consider how these independently, and in interaction with cultural and psychosocial factors, influence the experience of menopause.

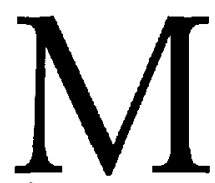

ore than 43 million American women are over the age of 45 (Theisen, Mansfield, Seery, \& Voda, 1995), a number that will increase to 52.5 million by the year 2000 (Mansfield \& Voda, 1993). These women may expect to live one third or more of their lives in the postmenopause, or period of life following menopause (Anderson, Hamburger, Liu, \& Rebar, 1987; Ferguson, Hoegh, \& Johnson, 1989). The experience of biologically timed menopause occurring in midlife serves as a rite of passage into later life, a passage that begins in the fourth decade and may extend for more than 10 years (Mansfield, Voda \& Koch, 1995). During this time, women experience significant changes in biological, psychological, and social functioning-changes that are not well understood and for which individual responses are highly variable (RosvoldBrenholtz, 1995; Sheehy, 1993).

The responses women have to menopause are related to the meanings they ascribe to it. These meanings are strongly influenced by not only the information available to them but also the context of the information (Mansfield \& Voda, 1993). The majority of research and literature related to menopause is generated from a biomedical paradigm that emphasizes symptomatology and disease (Rostosky \& Travis, 1996) and contextually, we believe, supports the ageism and sexism in American society. In a review of research literature spanning the years 1984 to 1994, Rostosky and Travis noted the lack of models that were developmental and contextually sensitive.

Counselors are in an ideal position not only to provide much needed accurate information (Mansfield, Theisen, \& Boyer, 1992) but also to create a context that supports de- fining menopause as a normative midlife transition, an approach that is critical for understanding female midlife development and for providing a basis for understanding later adult life (Matthews, 1992). The purpose of this article is to provide an understanding of the biomedical paradigm and how it both independently and collectively, with cultural and psychosocial paradigms, influences the experience of menopause. The adoption of an integrative perspective is suggested as a basis for counseling interventions, illustrated by a seven-phase guide to help women develop a personal approach to menopause.

\section{THE BIOMEDICAL PARADIGM}

A paradigm is a basic schema that organizes the way people think, circumscribing and setting boundaries for knowing and understanding (Babbie, 1989; Glanz, Lewis, \& Rimer, 1997). Paradigms integrate beliefs, values, attitudes, observations, and interpretations (Kuhn, 1962). To understand how menopause is conceptualized in the United States (U.S.), it is helpful to review the paradigms from which the concepts are formed. In the U.S., the biomedical paradigm is the most influential (Gannon \& Ekstrom, 1993).

\section{Menopause Defined as a Medical Condition}

The twentieth century dawned with women rarely outliving menopause. If they had been fortunate enough to survive the ravages of childhood diseases, they characteristically grew up, bore eight children, and then died (Sheehy, 1993). Thirty was considered middle aged (Sheehy, 1993) with menopause heralding in old age around the late forties. Greer

Shirley B. Huffman is a doctoral candidate, and Jane E. Myers is a professor, both in the Department of Counseling and Educational Development, University of North Carolina at Greensboro. Correspondence regarding this article should be sent to Shirley B. Huffman, PO Box 1522, Hickory, NC 28603 (c-mail: sbhuffman@aol.com). 
(1991) shed light on the prevalent attitude toward menopause in the 1930s with the following definition from a leading medical publication of that time: "The climacteric is an indication for woman that the period of her vigor is beginning to disappear forever. With more or less rapid steps but steps which admit of no return, woman now proceeds toward old age" (p. 41). A later medical publication read, "After the last planned pregnancy, the uterus becomes a useless, bleeding, symptom-producing, potentially cancerbearing organ and therefore should be removed" (Greer, 1991, p. 44).

In the 1940s, inexpensive estrogens were produced, and the biomedical idea that menopause was a changeable, physiological event gained in popularity (Gannon \& Ekstrom, 1993). In 1966, Robert Wilson published Feminine Forever, and launched the American medicalization of menopause. He identified estrogen loss as the culprit of the "disease" and initiated an aggressive medical practice of prescribing estrogen replacement (Matthews, 1992). Today, the biomedical model of menopause is deeply entrenched in America. Presently, an estimated 6 million menopausal and postmenopausal American women take estrogen (Lark, 1994)

\section{Defining Terms}

Although menopause is defined by medical science, it lacks one clear and specific meaning (Pearce, Hawton, \& Blake, 1995). The term may refer to a single event, the cessation of menses, or to a process that involves the stages of perimenopause, menopause, and early postmenopause (Hammond, 1994). Any number of criteria may be used to denote these stages, such as age, menstrual cycle patterns, presence of symptoms, or hormone levels (Mansfield et al., 1995). The use of different operational definitions and inclusion criteria in research creates serious problems when attempting to compare results across studies.

Menopause as a single event. The most commonly accepted definition of menopause states that menses must have ceased for at least 1 year (O'Connor et al., 1995). Determining the last menses is difficult because irregularity of cycles characterizes the years prior to menopause. This definition proves to be of little practical benefit to women, because it determines menopause retrospectively and ignores the years of change that precede it (Matthews, 1992). Many women are surprised by the biological and psychological symptoms that occur much earlier than the anticipated cessation

Menopause as a process. The terms menopause and climacteric are used interchangeably to refer to the total process of menopause-related changes, a pracess involving several stages and encompassing as many as 15 years of a woman's life (Gannon \& Ekstrom, 1993). The stages include perimenopause, menopause, and early postmenopause (Oldenhave \& Netelenbos, 1994). Only premenopause is excluded, because it represents all of the years that precede any changes due to menopause (Byyny \& Speroff, 1990).
Perimenopause. Perimenopause precedes menopause and is usually characterized by irregularity in menstrual cycles or changes in duration and amount of menstrual blood flow, or both (Oldenhave \& Netelenbos, 1994). Perimenopause is a significant stage because the physical and emotional changes that are associated with menopause begin in these 10 or more years before actual cessation of menstruation (Matthews, 1992). Oldenhave and Netelenbos reported that as women move from premenopause to perimenopause, there is a threefold increase in reported symptoms such as joint pain, forgetfulness, worrying about their bodies, being constipated, and having dizzy spells. With approximately $25 \%$ of women experiencing the onset of perimenopause before the age of 43 (Oldenhave \& Netelenbos, 1994), many women in their late 30 s and early 40 s are caught off guard, unaware that menopausal changes related to hormone fluctuations can begin so early in life. Mansfield et al. (1995) noted the regrettable neglect in literature concerning this particular stage, stating that many women believe the worst aspect of menopause is the lack of information and the uncertainty that surrounds the perimenopausal years.

Postmenopause. Postmenopause includes all of the years that follow menopause. The same criterion used to determine menopause, cessation of menses for l year, is also used to define postmenopause (Oldenhave \& Netelenbos, 1994). As illustrated by these definitions, from the time young women begin to menstruate until they die, they may be defined in menopausal terms.

\section{Etiology}

Etiologically, menopause may be the result of medical interventions such as hysterectomy, chemotherapy, or radiation, or the result of biologically timed aging processes. Although there is a wide age range for onset of biologically timed menopause, 39 to 59 (Oldenhave \& Netelenbos, 1994), the median age is 51 (Rosvold-Brenholtz, 1995). Etiology is not fully understood, but it is believed that menopause occurs at the close of a woman's reproductive years due to changes in the hypothalamus, pituitary, and ovaries. This results in loss of estrogen and progesterone normally produced in the ovaries. Although other areas of the body continue to produce these hormones, the amount is minuscule compared with the ovarian source (Hammond, 1994; Kamen, 1993). Certain physiological and psychological symptoms are associated with this change in hormone levels, but many confounding variables (e.g., attitudes and beliefs about menopause, stressful life events, and fear of the changes associated with aging) make the identification of symptoms uniquely attributable to menopause a difficult task (Carolan, 1994; Gannon \& Ekstrom, 1993; O'Connor et al., 1995).

\section{Symptomatology}

There is a wide variation in number and severity of symptoms experienced by menopausal women. Although the 
general population reports few problems, a subset of helpseeking women experience sequelae that seriously disrupt their lives (Anderson et al., 1987; Morse et al., 1994). Hundreds of symptoms have been associated with menopause, but the most common ones include hot flashes, vaginal dryness, reduced libido, sleep disturbance, irritability, depression, anxiety, palpitations, headaches, poor concentration, forgetfulness, and fatigue (Gannon, 1993; Morse et al., 1994; Rosenberg, Kroll, \& Vandromme, 1996; Teaff \& Wiley, 1996).

Hot flashes and other vasomotor symptoms. Hot flashes, also known as hot flushes, belong to a category of symptoms known as vasomotor or autonomic nervous system symptoms and are described as sudden sensations of heat in the face, neck, and chest. They may be accompanied by perspiration and shivering and other vasomotor symptoms such as increased heart rate (Hunter \& Liao, 1995) and feelings of irritation, anxiety, or panic (Oldenhave \& Netelenbos, 1994). Night sweats, hot flashes that occur during sleep, are less prevalent but are often disruptive to sleep (Hunter \& Liao, 1995). Women may be awakened many times during the night feeling hot, cold, or drenched with perspiration. Such sleep disturbance may result in fatigue and irritability (Rosenberg et al., 1996). From a survey of 5,213 women ages 39 to 60 , Oldenhave and Netelenbos found that hot flashes were reported by $41 \%$ of women age 39 and over who were still experiencing regular cycles. By the onset of menopause, the percentage of women reporting hot flashes rose to $85 \%$. Thirty percent of women close to menopause characterized their hot flashes as severe. Frequent flashes have a profound effect on the quality of life, because they are associated with complaints such as tenseness, tiredness, irritability, headaches, muscle and joint pain, and depression (Oldenhave \& Netelenbos, 1994). Hot flashes are both the most common reason women seek medical attention (Hunter \& Liao, 1995) and the most common reason doctors prescribe hormone replacement (Rosenberg et al., 1996). Estrogen has been shown to be effective in relieving vasomotor symptoms (Ferguson et al., 1989; Hammond, 1994).

Vaginal dryness. Vaginal dryness, another symptom associated with menopause, is reported by $16 \%$ of regularly menstruating women aged 39 . This percentage increases to $40 \%$ to $45 \%$ of women who are 4 to 10 years postmenopause (Ferguson et al., 1989). Vaginal dryness is linked with a decrease in sexual desire and enjoyment and difficulty with orgasm due to pain and discomfort. Estrogen has been successful in diminishing or relieving vaginal dryness (Ferguson et al., 1989); however, as Mansfield et al. (1995) noted, problems with sexuality may be due to more complex factors than purely biomedical issues.

Psychological distress. An underlying theme in medical literature is that menopausal women are depressed (Dennerstein, Smith, \& Morse, 1994). Dennerstein et al. cited Ballinger as attributing this to the experience of gynecologists with their clinic populations. Broad generalizations were made from these nonrepresentative samples that reported considerably more psychological and physiological problems than did the general population of menopausal women (Anderson et al., 1987; Coleman, 1993; Dennerstein et al., 1994; Morse et al., 1994). Anderson et al. found that, of those women seeking medical consultation for menopausal symptoms, $65 \%$ reported varying degrees of depression. Pearce et al. (1995), in a review of psychological symptoms in menopause, found conflicting results among studies of general populations. Pearce et al. noted that three prospective studies, as well as several large cross-sectional studies, showed no significant increases in depression. Several other well-designed studies demonstrated a slight increase in depressive mood during the stage of perimenopause. Matthews (1992) suggested that, if there is a slight increase in depression during perimenopause, it may be attributable to women experiencing vasomotor symptoms for the first time. She noted that depressive symptoms seem to subside as women adjust to these occurrences.

\section{Major Diseases Associated With Menopause}

Although the majority of women do not find the symptoms of the climacteric particularly troublesome (Busch, Zonderman, \& Costa, 1994; Logothetis, 1991), all must consider the risk for developing the associated diseases. Research indicates that menopausal and postmenopausal women are at risk for developing heart disease and osteoporosis and that increased risk of breast cancer is possibly linked with the hormone replacement therapy (HRT) used to prevent these conditions (Colditz et al., 1995; Hammond, 1994; Oldenhave \& Netelenbos, 1994).

Osteoporosis. Osteoporosis is a condition in which the bones lose significant mass and strength, often resulting in fractures (Hammond, 1994). Seventy-five percent of the bone loss that occurs within the first 20 years postmenopausally is attributable to estrogen deficiency (Byyny \& Speroff, 1990). It is estimated that 1 in 3 American women will develop some complication from this disease (Kamen, 1993). Postmenopausally, osteoporosis causes 1.3 million fractures a year, 120,000 of these being devastating hip fractures that occur in women over 45 (Ferguson et al., 1989). Hip fractures result in the following grim statistics: $75 \%$ of the victims will lose their independence, $25 \%$ will require long-term skilled care, and $15 \%$ will die within 1 year of the break (Ferguson et al., 1989). Between 7 and 10 billion dollars are spent each year on the complications of osteoporosis (Hammond, 1994)

Studies consistently support the effectiveness of HRT in preventing or retarding osteoporosis (Garton, Reid \& Rennie, 1995; Hammond, 1994; Oldenhave \& Netelenbos, 1994). As early as 1975, a 10-year prospective study of the effects of estrogen and progesterone on osteoporosis showed that if HRT was instituted within 3 years of menopause, the loss of bone mass could be reversed, and if started after 3 years it could at least be halted (Nachtigall, Nachtigall, Nachtigall, \& Beckman, 1979). Because the benefits of HRT are quickly lost once treatment is stopped, some physicians recommend maintaining therapy for 10 years, if not indefinitely (Rosenberg et al., 1996). 
Coronary heart disease. Another illness, coronary heart disease (CHD) is the leading cause of death among postmenopausal women, claiming approximately 250,000 lives each year and accounting for at least one third of age-related deaths (Byyny \& Speroff, 1990; Rosenberg et al., 1996). A review of literature found overwhelming support that estrogen reduces the risk of CHD (Byyny \& Speroff, 1990). A meta-analysis of observational studies suggests as much as a $50 \%$ reduced risk in postmenopausal women taking estrogen (Writing Group, 1995). The National Institute of Health's (NIH) Postmenopausal Estrogen/Progesterone lntervention trial (PEPI), a 3-year landmark study, researched the effects of adding progesterone to the hormone regimen and concluded that although unopposed estrogen provides the best cardiovascular protection, the protection afforded by estrogen/progesterone is similar (Writing Group, 1995).

Breast cancer. In light of the well-accepted benefits of HRT, the major complicating factor for women is the risk of breast cancer. Breast cancer kills an estimated 46,000 women each year (Byyny \& Speroff, 1990). Once again, research has yielded conflicting results. In 1995, within 2 months of each other, two major medical journals reported studies finding opposite results (Rosenberg et al., 1996). The Journal of the American MedicalAssociation published an article with findings from a population-based, case-control study of women ages 50 to 64 , involving 537 patients with primary breast cancer and 492 randomly selected women in the control group without a history of breast cancer. They concluded that estrogen and progesterone did not seem to be associated with an increased risk of breast cancer in middle-aged women (Stanford et al., 1995). The New England Journal of Medicine published results from a follow-up of the Nurses' Health Study, a prospective cohort study that looked at 725,550 person-years of follow-up, that concluded just the opposite (Colditz et al., 1995). A small but significantly increased risk of breast cancer in women using estrogen alone and estrogen with progesterone was detected, with increased risk particularly evident in women who had used HRT for 5 or more years. In the worst-case scenario, if longterm HRT increases a woman's risk for breast cancer by $30 \%$, this does not mean that she stands a $30 \%$ risk for contracting the disease. Rather, it means that the accepted rate of $10 \%$ for the whole female population is increased by $30 \%$, translating into a 13\% risk for long-term users of HRT (Teaff \& Wiley, 1996). It also seems that HRT does not cause breast cancer but that it may accelerate growth of existing breast cancer (Teaff \& Wiley, 1996).

\section{Hormone Replacement Therapy}

As well as relieving vasomotor symptoms and vaginal dryness and protecting against osteoporosis and heart disease (Byyny \& Speroff, 1990; Ferguson et al., 1989; Garton et al., 1995; Hammond, 1994), HRT may also improve psychological (Ditkoff, Crary, Cristo, \& Lobo, 1991) and cognitive (Kimura, 1995) functions. Taken together, these represent sizable benefits, yet women find the topic of HRT confus- ing and frightening (Nachtigall, 1990) and express a need for accurate unbiased information (Mansfield et al., 1992). A Gallop survey conducted in 1993 of 833 women (ages 45-60) revealed that women believed their physicians had failed to supply adequate information about such things as long-term effects of estrogen deficiency, treatment options, and possible side effects (Abraham, Perz, Clarkson, \& Llewellyn-Jones, 1995). Although it is estimated that $40 \%$ of American menopausal and postmenopausal women use HRT (Lark, 1994), up to $50 \%$ discontinue its use within the 1st year (Rosvold-Brenholtz, 1995), citing fear of cancer and displeasure with bleeding as determining factors (Nachtigall, 1990).

Because health care studies in the U.S. historically have been based on the male population with results extrapolated to women, definitive studies investigating women's health issues are usually lacking (Bocchino, 1992). Shortly after Bernadine Healy was appointed director of the $\mathrm{Na}$ tional Institute of Health in 1991, she launched the NIH Women's Health Initiative, an extensive study of women's health issues (Bocchino, 1992). This represents the most expansive study of women's health ever attempted, involving 164,500 women (Matthews et al., 1997). Included in this study are components that examine the effects of estrogen and progesterone on the overall health of women (Matthews et al., 1997). Definitive results are not expected until early in the twenty-first century.

Estrogen is recommended for menopausal women who have had hysterectomies, whereas estrogen plus a progestin (synthetic progesterone) or a natural progesterone is recommended for those who have not had hysterectomies (Rosenberg et al., 1996). Progesterone protects the lining of the uterus from overgrowth that can become cancerous and also affords some protection against osteoporosis (Kamen, 1993; Lee, 1996). It protects the uterus either by inducing a sloughing off of the excessive lining as a monthly period or by simply preventing the proliferation (Love, 1997). Women strongly prefer the latter, because it does not involve monthly bleeding (Mansfield \& Voda, 1993). This can usually be accomplished by regulating dosage and length of time progesterone is given each month (Teaff \& Wiley, 1996).

There is great variety in types, combinations, strengths, and routes of administration of HRT (Love, 1997), as well as wide variation in each woman's response (Teaff \&Wiley, 1996). It is beyond the scope of this article to discuss HRT in detail. The interested reader can find more information on this subject from their professional health care provider, library, or books such as Dr. Susan Love's Hormone Book (Love, 1997). It is normal to need three to five visits with one's medical health care provider to achieve the best results (Teaff \& Wiley, 1996).

\section{Alternative Theatments}

Alternative remedies used to relieve menopausal symptoms and support general health include the use of proper diet, exercise, vitamins, minerals, and herbs (Kamen, 1993; Love, 
1997; Murray, 1994). Love suggested that initial research on alternative treatments can be done by checking the literature and talking to friends who have used them but that it is wise to seek the advice of a qualified practitioner before beginning treatment.

There is growing interest in a class of naturally occurring plant hormones called phytoestrogens that are similar to human estrogens. Soybeans, soy sprouts, peas, and yams are rich sources (Healy, 1995). High dietary intake of these phytoestrogens, such as is observed in Japanese women, has been linked not only with fewer menopausal symptoms but also to a lower incidence of breast cancer (Healy, 1995). The Soy Estrogen Alternate Study, under the auspices of $\mathrm{NIH}$, is presently underway at Bowman Gray School of Medicine and early results seem to support the use of the soybean as an estrogen replacement source (B. Earl, personal communication, February 9, 1997). Natural progesterone derivatives from the South American yam are being marketed in topical cream forms (Kamen, 1993). In addition, micronized progesterone, a natural progesterone that can be taken by mouth and causes fewer side effects than the popular synthetic progesterone, is now available in America (Lark, 1994). While women await conclusive research on both alternative and traditional treatment of menopause, they will have to make individual decisions based on an assessment of their symptoms, health status, family history, and personal preferences.

\section{BEHAVIORAL SCIENCE PARADIGIAS}

As is the nature of a paradigm, the biomedical paradigm creates boundaries for understanding, experiencing and treating menopause. Unfortunately, the context is negative in many cases, but the content is still valuable. Women need to understand their biology and the physiological changes associated with aging and menopause Personal baseline medical information, knowledge of family medical history, and understanding of health risks are essential elements for understanding the changes of menopause. Yet, taken independently, this paradigm is reductionistic and frequently discouraging to women. As a defining model, it lacks the breadth and depth to explain the complexity of this midlife transition, and, as a treatment model, it can be both confusing and frightening. We contend that it is only with the inclusion of other paradigms that one begins to understand the challenge and richness of this time of change in a woman's life.

\section{Cultural Paradigm}

The relationship between the biomedical and cultural paradigms of menopause is symbiotic, each supporting and interacting with the other. The lack of female-normed medical research (Matthews, 1992) is understandable in light of the cultural devaluation of women in the U.S. (Agonito, 1977) and the cultural sexism and ageism that are supported by medical perceptions of menopausal women as psychologically and physically unstable (Agonito, 1977; Greer,
1991). They have historically combined to create a difficult environment for menopausal women (Greer, 1991).

U.S. culture, to a significant degree, has based a woman's worth on her sexuality, attractiveness, and youth, qualities that are mistakenly believed to be lost at menopause (Carolan, 1994; Gergen, 1990). Cultural stereotypes historically have portrayed climacteric women as old, disease ridden, emotionally unstable, and even as useless (Agonito, 1977; Formanek, 1990; Greer, 1991).

Bowles (1990) theorized that a cultural paradigm greatly influences how a woman experiences menopause. She posits that a causative pathway begins with cultural attitudes and beliefs, leads to personal attitudes and expectations, and ultimately influences how a woman experiences menopause. Cross-cultural research provides some of the strongest evidence of this link. For example, in cultures in which aging women are afforded an elevation in status, such as in certain parts of India, South Africa, and in some Native American tribes, there are few problematic symptoms reported (Carolan, 1994; Griffin, 1977; Patterson \& Lynch, 1988). Other studies (Avis \& McKinlay, 1991; Hunter, 1990) also support the positive correlation between personal attitudes about menopause and personal experience.

The cultural ageism and sexism in America is believed to contribute to women's perceptions such as associating no sense of achievement, or gained status, with menopause (Mansfield \& Voda, 1993), fear of physical and sexual deterioration (Berkun, 1986; Mansfield et al., 1995), and anticipation of depression (Matthews, 1992). Matthews reported that $80 \%$ of the premenopausal women who participated in the Healthy Women Study believed that women in general were liable to get depressed during menopause. Fiftyfive percent believed they, themselves, were liable to experience depression during menopause.

American women do not want to age. Rossi (1980) found no midlife woman who wanted to be older than she was, and half wanted to be under the age of 30 . Women are hesitant to associate themselves with this marker of the aging process (Carolan, 1994; Greer, 1991; Mansfield et al., 1995; Sheehy, 1993). Gannon and Ekstrom (1993) found that younger women consistently viewed menopause more negatively than did menopausal and postmenopausal women, suggesting that because menopause is probably not of major concern to them yet, their attitudes reflect the dominant cultural perspective. Women in midlife reveal concerns about body image as they seek to reconcile cultural images of what women's bodies should look like with the changes they are experiencing (Berkun, 1986; Carolan, 1994; Chrisler \& Ghiz, 1993). The serious absence of positive role images of aging women (Mansfield \& Voda, 1993; Theisen et al., 1995) complicates this process.

\section{Psychosocial Paradigm}

The symbiotic relationship between the biomedical and cultural paradigms of menopause also interacts with complex and often difficult midlife psychosocial factors. Meno- 
pause is only one of many changes that occur in midlife, a time when there is a shift in roles, responsibilities, and relationships (Bromberger \& Matthews, 1996). Large epidemiological studies in the U.S. and Great Britain support the belief that psychosocial stressors and symptomatology are related (Bromberger \& Matthews, 1996; Kaufert, Gilbert, \& Tate, 1992; McKinlay \& McKinlay, 1987; Popay, Bartley, \& Owen, 1993). Carolan (1994) emphasized the adverse effects of stressful midlife circumstances (e.g., ailing husbands, widowhood, caring for elderly parents, loss of employment, health status, and coping with adolescent children) and stressed the importance of social support.

Loss is a prominent theme of midlife. It is during this time that women may first deal with loss of youth (Ellman, 1996), loss of important roles such as those of procreativity and parenting, loss of status, and loss of economic security (Patterson \& Lynch, 1988). Some of these losses, such as loss of status and economic security, are the result of years of unequal social status for women and older persons, whereas other losses are associated with developmental tasks of a poorly understood stage in life (Carolan, 1994). Cook and Greene (1981) found that the loss of significant others was the primary stressful life event associated with psychological symptomatology in menopause. These losses have profound implications for menopausal women in midlife as they struggle with transition and change.

\section{AN INTEGRATIVE PEESPECTIVE}

We believe defining menopause in terms of disease disqualifies it as a normal life transition (Carolan, 1994). Yet denying the impact of biomedical factors ignores the reality of physiological change, possible disruptive symptomatology, and health risks. One value of an integrative perspective, which combines paradigms from both biomedical and behavioral sciences, is its ability to reframe negative medical issues in more contextually positive terms. There is great variability within each menopausal woman's experience and among individual women, pointing to the need for flexibility and breadth in definition, research, and services (Carolan, 1994). For example, women who seek relief from vasomotor symptoms or anxiety should not be stigmatized or embarrassed but helped, whereas women who "breeze through" this transition, possibly unaware of health risks, need information on the potential for osteoporosis and heart disease.

It is the combination of paradigms from both medical and behavioral sciences that provides a broad-based multidimensional perspective of menopause, one that allows counselors to appreciate each woman as both alike and different from other women in this time of change. An integrative perspective provides an opportunity to reframe biomedical and psychosocial changes in developmental terms as part of a normal and expected transition (Gannon \& Ekstrom, 1993). This approach engenders responsibility and empowerment of women, as it returns to them a sense of control over their bodies and lives, encourages them to be fully informed on the issues of menopause, and promotes a healthy lifestyle (Carolan, 1994).

Central to the developmental paradigm is the concept that menopause is a midlife transition, a normative time of change and adaptation. Patterson and Lynch (1988) suggested that Schlossberg's (1981) theory of transition is helpful both in understanding the meaning menopause holds for a particular woman and in understanding her ability to adjust. This theory emphasizes that reactions to transition depend on the context in which they occur and the impact they have on individual lives. It fits well into an integrative approach to menopause, because it emphasizes assessing diverse factors such as socioeconomic status, health state, support systems, values and beliefs, perceptions of gains and losses, and degree of stress. This theory further posits that times of transition often require new networks of relationships and new ways of seeing oneself, skills that counselors are adept in facilitating.

\section{COUNSELING IMPLICATIONS}

The many changes that occur during menopause, combined with the confusion and fear associated with it, will make this a troubling time for some women. We believe counselors are in a unique position to provide accurate biomedical information within an integrative approach that conceptualizes menopause as a normative midlife transition.

Defining menopause as a transition creates the image of time-limited disruptions and encourages assessments of both losses and gains (Carolan, 1994). It provides opportunities to grieve the losses of midlife as well as count the gains, to redefine one's identity, and to experience new beginnings (Schlossberg, Waters, \& Goodman, 1995). Counselors can provide support and encouragement, social networks through group experiences, and help to plan and implement a personal approach to this midlife process. Approaching menopause as a midlife transition engenders a sense of control and empowerment while setting a positive stage for the next trimester of life.

\section{Designing a Personal Approach}

The following is a seven-phase guide that counselors may find helpful when working with menopausal women. This guide is not meant to be a rigid chronological process or to represent all possible considerations but rather a framework that reflects the multiple and complex aspects of menopause. Phases may be blended, rearranged, and modified to meet individual client needs and fit within any existing time constraints. The purpose of the guide is to assist clients in their adaptation to this midlife transition, to help them understand, define, and respond to their own unique experiences of the climacteric.

Phase 1: Education. Because people ascribe meaning to their experiences based on the information available to them (Mansfield \& Voda, 1993), counselors can educate clients by providing accurate, unbiased information that is repre- 
sentative of the complex nature of menopause. As counselors listen to clients for insight into how they perceive and respond to menopause, counselors can raise questions that call attention to misconceptions and misinformation. Sharing of information and increasing awareness is the first phase of this process. Of course, counselors will first need to educate themselves if their work with clients at this stage is to be successful.

Phase 2: Recognizing the importance of the biomedical issues. Initially, clients need to schedule a consultation with their medical health care provider to discuss changes related to menopause (Teaff \& Wiley, 1996). At this time, menopause can be discussed from a biomedical perspective that provides accurate information and treatment recommendations. Counselors can encourage women to choose health care professionals who are comfortable cocreating a health plan, professionals who take women's concerns seriously, and with whom they can dialogue.

Phase 3: Self-assessment. The questions in this phase are reflective of key elements in Schlossberg's model of adaptation (Schlossberg et al., 1995), which focus on context and impact of biomedical, cultural, and psychosocial factors on the lives of women. A counselor can facilitate this stage by having a client ask herself the following:

- How have sociocultural attitudes about aging and menopause affected my attitudes?

- What are my expectations and fears about menopause?

- What are my most immediate needs and concerns? Are they biomedical, cultural, and psychosocial?

- How healthy is my lifestyle in terms of diet, exercise, smoking, excessive alcohol intake, use of over-thecounter or other drugs and medications?

- What is my family medical history in terms of osteoporosis, heart disease, and breast cancer?

- What are the major stressors in my life?

- What can be done to reduce the stress?

- How much thought and effort have I put into taking care of myself lately?

- What symptoms have I noticed that may be related to perimenopause or menopause?

- What are my information gaps about menopause?

- What other questions do I have?

Phase 4: Dialogue and definition. Women need support, encouragement, and someone to talk to-someone who can help them make sense of their experience (Mansfield et al., 1992; Mansfield \&Voda, 1993; Schlossberg, 1981). As Gilligan (1993) reminded us, women define themselves in relation to and connection with others. Because normative experiences of midlife and menopause are lacking, women must define what is normal for them, as they interact with other women or family members. Counselors can facilitate this process by providing one-to-one counseling and by developing support groups and other interactive experiences. Conceptualizing menopause as a midlife transition provides opportunities to reframe perceived endings and losses in terms of new beginnings (Schlossberg et al., 1995). Questions for women to consider in this phase include the following:

- Who are my support people who will listen to me, dialogue with me, and help me make sense of my experience?

- Who can I taik to in my family?

- What are other women thinking and experiencing who are at the same stage in life?

- What was my mother's experience?

- What was the experience of older friends and relatives?

- What are the realities of my own experience? What help do I need?

- How do I anticipate my life changing in terms of losses? Gains?

- What new beginnings would I like to see happen? How can I help this happen?

- How do I want to define menopause?

- How do I want to redefine myself as I move through this transition?

- Who is in charge of my menopause?

Phase 5: Using resources and creating a plan. It is important to explore with clients their perceived power to choreograph their own response to menopause (Carolan, 1994). Counselors can encourage clients to become empowered through knowledge of resources and options, sources that include both alternative and traditional medicine. For those who have access to this resource, The North American Menopause Society and other excellent resources can be found on the World WideWeb (http://www.menopause.org/ news.htm).

Counselors can encourage women to develop a personal plan for the climacteric that is broader than a biomedical perspective, a plan that reflects the nature and scope of this midlife transition (Carolan, 1994; Patterson \& Lynch, 1988). This is an appropriate foundation for a collaborative relationship with one's medical health care provider. Counselors also provide support, encouragement, and problem-solving help to women, while also reminding them that menopause is an opportunity to explore new horizons (Schlossberg et al., 1995). The plan can include practical solution-oriented interventions, such as ways to cope with disrupted sleep patterns, or weight maintenance, as well as more abstract components, such as scheduling time to reflect, redefine, and plan for the future.

Phase 6: Implementing the plan. Phase 6 can be empowering as women assume responsibility for implementing their plans. Counselors can remind clients to be patient with themselves, to implement changes by degrees, and to seek a partner or group with whom to share their experiences (Schlossberg et al., 1995). The responses of women to menopause and hormone therapy vary dramatically and often require a trial-and-error approach to find the best combination of hormones (Teaff \&Wiley, 1996). If clients experi- 
ence troublesome physiological symptoms, counselors can encourage them to contact their medical health care provider for assistance. Counselors can encourage women to be assertive and to collaborate with their medical team until satisfactory results are obtained.

Phase 7: Reevaluation and adjustments. In Phase 7, counselors need to remind clients that menopause is characterized by variability and change. Counselors can help normalize symptomatology and remind clients of the "trial and error" approach to coping. Priorities and circumstances change as women move through menopause, requiring updating and adjustment of the plan. For example, disruptive symptoms may subside and issues of changing roles may become the emphasis, or just the opposite may occur with psychosocial issues being replaced by biomedical concerns. It may be helpful to remind clients who struggle with severe symptoms that menopause is a time of transition, meaning it will end. Until then, creativity, support, and encouragement are critical.

\section{CONCLUSION}

The number of women who will seek counseling services, for any number of issues related to menopause, will increase as America "ages." Counselors need to be knowledgeable about and comfortable with the topic to provide helpful services. By developing an integrative perspective, counselors can reframe valuable biomedical information in the contextually positive terms of normative midlife transition. This approach provides clients with a multidimensional base for conceptualization of this complex experience. Counselors can help clients understand the meaning that menopause holds for them within the context of their own lives, help them plan and implement a proactive approach to this midlife process, and set a positive stage for the next trimester of life.

\section{REFERENCES}

Abraham, S., Petz, J., Clarkson, R., \& Llewellyn-Jones, D. (1995). Australian women's perspective of hormone replacement therapy over 10 years. Maturitas, 21, 91-95

Agonito, R. (1977). History of ideas on women. New York: Berkley Publishing Group.

Anderson, E. A., Hamburger, S., Liu, J. H., \& Rebar, R. W. (1987). Characteristics of menopausal women seeking assistance. American Journal of Obstetrics and Gynecology, 156, 428-433.

Avis, N. E., McKinlay, S. M. (1991). A longitudinal analysis of women's attitudes toward the menopause: Results from the Massachusetts Women's Health Study. Maturitas, 14, 65-79.

Babbie, E. (1989). The practice of social research (5th ed.). Belmont, CA: Wadsworth.

Berkun, C. S. (1986). In behalf of women over 40: Understanding the importance of the menopause. Social Work, 31, 378-384.

Bocchino, C. A. (1992). An interview with Bernadine P. Healy. Nursing Economics, 10, 387-392.

Bowles, C. L. [1990). The menopausal experience: Sociocultural influences and theoretical models. In R. Formanek (Ed.), The meanings of menopause: Historical, medical, and clinical perspectives (pp. 157-177). Hillsdale, NJ: Analytic Press.
Bromberger, J. T., \& Matthews, K. A. (1996). A longitudinal study of the effects of pessimism, trait anxiety, and life stress on depressive symptoms in middle-aged women. Psychology and Aging, 11, 207-213.

Busch, C. M. Zonderman, A. B. \& Costa, P. T. (1994). Menopausal transition and psychological distress in a nationally representative sample Journal of Aging and He'alth, 6, 209-228.

Byyny, R. L., \& Speroff, L. (1990). A clinical guide for the care of older women. Baltimore: Willians and Wilkins.

Carolan, M.T. [1994). Beyond deficiency: Broadening the view of menopause. The Joumal of Applied Gerontology, 13, 193-205.

Chrisler, J. C., \& Ghiz, L. (1993). Body image issues of older women: Special issue. Women and Therapy, 14, 67-75.

Colditz, G. A., Hankinson, S. E., Hunter, D. J., Willett, W. C., Manson, J. E., Stampfer, M. J., Hernekens, C., Rosner, B., \& Speizer, F. E. (1995). The use of estrogen arid progestins and the risk of breast cancer in postmenopausal women. The New England Joumal of Medicine, 332, $1589-1593$.

Coleman, P. M. (1993). Depression during the female climacteric period. Journal of Advanced Nursing, 18, 1540-1546.

Cook, D. J., \& Greene, J. C. (1981). Types of life events in relation to symptoms at the climacterium. Journal of Psychosomatic Research, 25, 5-11.

Dennerstein, L., Smith, A., \& Morse, C. (1994). Psychological well-being, mid-life and the menopause. Maturitas, 20, l-11.

Ditkoff, E. C., Crary, W. G., Cristo, M., \& Lobo, R. A. (1991). Estrogen improves psychological function in asymptomatic postmenopausal women. Obstetrics and Gynecology, 78, 991-995

Ellman, J. P. (1996). Analyst and patient at mid-life. Psychoanalytic Quarterly, 65, 353-371

Ferguson, K. J., Hoegh, C., \& Johnson, S. J. (1989). Estrogen replacement therapy: A survey of women's knowledge and attitudes. Archives of Internal Medicine, I49 133-136.

Formanek, R. (Ed.) (1990). The meanings of menopause: Historical medical and clinical perspectives. Hillsdale, NJ: The Analytic Press

Gannon, L. (1993). Meropausal symptoms as consequences of dysrythmia. Journal of Behavioral Medicine, 16, 387-402.

Gannon, L., \& Fkstram, B. (1993). Attitudes toward menopause: The influence of sociocultural paradigms. Psychology of Women Quarterly, 17, 275-288

Garton, M., Reid, D. \& Rennie, E. (1995). The climacteric, osteoporosis and hormone replacernent: Views of women aged 45-49. Maturitas, 27, 7-15.

Gergen, M. (1990). Finished at 40: Women's development within the patriarchy. Special issue: Women at mid-life and beyond. Psychology of Women Quarterly, 14, 471-493.

Gilligan, C. (1993). In a different voice: Psychological theory and wornen's development. Cambridge, MA: Harvard University Press.

Glanz, K., Lewis, F. M., \& Rimer, B. K. (1997). Health behavior and health education ( 2 nd ed.). San Francisco: Jossey-Bass.

Greer, G. (1991). The change. New York: Ballantine Books.

Griffin, J. (1977). A cross-cultural investigation of behavioral changes at menopause. Social Science Journal, 14, 49-55.

Hammond, C. B. (1994). Climacteric. In J. R. Scott, P. J. DiSais, C. B. Hammond, \& W. N. Sfellacy (Eds.), Danforth's obstetrics and gynecology (7th ed., pp. 771-.790). Philadelphia: J. B. Lippincott

Healy, B. (1995). A new prescription for women's health. New York: Penguin Books.

Hunter, M. S. (1990). Psychological and somatic experiences of the menopause:A prospective study. Psychosomatic Medicine, 52, 357-367.

Hunter, M. S., \& Liao, K. (1995). A psychological analysis of menopausal hot flushes. British Journal of Clinical Psychology, 34, 589-599

Kamen, B. (1993). Hormone replacement therapy: Yes or na? Novato, CA: Nutrition Encounter Inc

Kaufert, P. A., Gilbert, P, \& Tate, R. (1992). The Manitoba project: A reexamination of the link between menopause and depression. Maturitas, $14,743-155$

Kimura, D. (1995). Estrogen replacement therapy may protect against intellectual decline in postmenopausal women. Hormones and Behavior, $29,312-321$. 
Kuhn, T. S. (1962). The structure of scientific revolution. Chicago: University of Chicago Press.

Lark, S. M. (1994), The estragen decision. Los Altos, CA: Westchester Publishing.

Lee, J. R. (1996). What your doctor may not tell you about menopause: The breakthrough book on natural progesterone. New York: Warner Books.

Logothetis, M. L. (1991). Women's decisions about estrogen replacement therapy. Western Journal of Nursing Research, 13,459-468.

Love, S. M. (1997). Dr. Susan Love's homone book. New York: Random House.

Mansfield, P. K., Theisen, S. C., \& Boyer, B. (1992). Mid-life women and menopause: A challenge for the mental health counselor. Journal of Mental Health Counseling, 14,73-83.

Mansfield, P. K., \& Voda, A. M. (1993). From Edith Bunker to the 6:00 news: How and what mid-life women leam about menopause: Special issue. Women \& Therapy, 14, 89-103.

Mansfield, P. K., Voda, A. M., \& Koch, P. B. (1995). Predictors of sexual response changes in hcterosexual mid-life women. Health Values, 19, 11-20.

Matthews, K.A. (1992). Myths and realities of the menopause. Psychosomatic Medicine, 54, 1-9.

Matthews, K. A., Shumaker, S. A., Bowen, D. J., Langer, R. D., Hunt, J. R., Kaplan, R. M., Klesges, R. C. \& Ritenbaugh, C. (1997). Women's health initiative; Why now? What is it? What's new? American Psychologist, 52, 101-116.

McKinlay, J. B., \& McKinlay, S. M. (1987). Depression in middle-aged women: Social circumstances versus estrogen deficiency. In M. R. Walsh (Ed.), The psychology of women: Ongoing debates (pp. 157-161). New Haven, CT: Yale University Press.

Morse, C. A., Smith, A., Dennerstein, L., Green, A., Hopper, J., \& Burger, H. (1994). The treatment-seeking woman at menopause. Maturitas, $18,161-173$.

Murray, M. T. (1994). Menopause Rocklin, CA: Prima Publishing.

Nachtigall, L. E. (1990). Enhancing patient compliance with hotmone replacement therapy at menopause. Obstetrics and Gynecology, 75, 77-80.

Nachtigall, L. E., Nachtigall, R. H., Nachtigall, R. D., \& Beckman, E. M. (1979). Estrogen replacement therapy I: A l0-year prospective study in the relationship to osteoporosis. Obstetrics and Gynecology, 53, 277-281.

O'Connor, V. M., Del Mar, C. B., Sheehan, M., Siskind, V., Fox-Young, S., \& Cragg, C. (1995). Do psycho-social factors contribute to symptom reporting by middle-aged women than hormonal status? Maturitas, 20, 63-69.

Oldenhave, A., \& Netelenbos, C. (1994). Pathogenesis of climacteric complaints: Ready for change? Lancet, 343, 649-653.

Patterson, M. M., \& Lynch, A. Q. (1988). Menopause: Salient issues for counselors. Journal of Counseling and Development, 67, 185-188.

Pearce, J., Hawton, K., \& Blake, F. (1995). Psychological and sexual symptoms associated with the menopause and the effects of hormone replacement therapy. British Journal of Psychiatry, 167, 163-173.

Popay, J., Bartley, M., \& Owen, C. (1993). Gender inequalities in health and social position, affective disorders and minor physical morbidity. Social Science and Medicine, 36, 21-32.

Rosenberg, S., Kroll, M., \& Vandromme, J. (1996). Decision factors influencing hormone replacement therapy. British Journal of Obstetrics and Gynecology, 103, 92-98.

Rossi, A. S. (1980). Life-span theories and women's lives. Signs, 6, 4-32.

Rostosky, S. S., \& Travis, C. B. (1996). Menopause research and the dominance of the biomedical model 1984-1994. Psychology of Women Quarterly, 20, 285-312.

Rosvold-Brenholtz, H. (1995). The menopause and hormone therapy. National Women's Health Report, 17, 1-5.

Schlossberg, N. K. (1981). A model for analyzing human adaptation to transition. The Counseling Psychologist, 9, 2-18.

Schlossberg, N. K., Waters, E. B., \& Goodman, J. (1995). Counseling adults in transition: Linking practice with theory. New York: Springer Publishing.

Sheehy, G. (1993). The silent passage. New York: Pocket Books.

Stanford, J., Weiss, N. S., Voigt, L. F., Daling, J. R., Habel, L. A., \& Rossing, M. A. (1995). Combined estrogen and progestin hormone replacement therapy in relation to risk of breast cancer in middle-aged women. Journal of the American Medical Association, 274, 137-142.

Teaff, N. L., \& Wiley, K. W. (1996). Perimenopause, preparing for the change. Rocklin, CA: Prima Publishing.

Theisen, S. C., Mansfield, P. K., Seery, B. L., \& Voda, A. (1995). Predictors of mid-life women's attitudes toward menopause. Health Value, 19, 22-31.

Wilson, R. (1966). Feminine forever. New York: Evans.

Writing Group for the PEPI Trial. (1995). Effects of estrogen or estrogen/progestin regimens on heart disease risk factors in postmenopausal women. Journal of the American MedicalAssociation, 273, 199-208. 